\title{
METAS DE SOCIALIZAÇÃO DE MÃES BAIANAS DE DIFERENTES CONTEXTOS SOCIOECONÔMICOS
}

\section{SOCIALIZATION GOAL OF MOTHERS FROM BAHIA IN DIFFERENT SOCIOECONOMIC CONTEXTS}

\author{
Maria Vitória de Carvalho Moinhos* \\ Eulina da Rocha Lordelo** \\ Maria Lúcia Seidl de Moura***
}

\begin{abstract}
Moinhos MVdC, Lordelo EdR, Moura MLSd. Metas de socialização de mães baianas de diferentes contextos socioeconômicos. Rev Bras Crescimento Desenvolv Hum 2007; 17(1):114-125.
\end{abstract}

\begin{abstract}
Resumo: Sistemas de crenças e práticas de cuidado parentais têm se tornado um tópico importante em psicologia do desenvolvimento, devido ás suas repercussões na qualidade do cuidado à criança e no desenvolvimento infantil.Tendo em vista a escassez de descrições sobre a realidade brasileira nesse aspecto, este estudo teve como objetivo caracterizar metas e estratégias maternas numa amostra da cidade de Salvador, relacionando-as com suas características sócio-demográficas. Participaram do estudo 50 mães com pelo menos um filho com idades entre zero a três anos que foram entrevistadas em suas residências e aplicados dois instrumentos: Inquérito sócio-demográfico e Entrevista sobre metas e estratégias de socialização. Os dados sócio-demográficos foram tratados conforme a Escala de Avaliação de Status Socioeconômico de Hollingshead e as metas de socialização foram analisadas a partir das categorias: auto-aperfeiçoamento, autocontrole, emotividade, expectativas sociais e bom comportamento. Os resultados não indicaram diferenças estatisticamente significativas entre os grupos em relação às metas de socialização, com exceção da subcategoria integridade pessoal e valores religiosos relativa à meta Expectativas sociais - mais enfatizada pelas mães de NSE baixo. Quanto às estratégias de ação, as mães dos dois grupos relataram adotar estratégias baseadas nos seus próprios recursos (Centradas em si). No conjunto, os resultados sugerem metas similares entre os dois grupos. Esses resultados são interpretados como expressão de um ambiente cultural relativamente homogêneo quanto a valores idealizados, um achado surpreendente, tendo em vista as grandes diferenças em nível socioeconômico observadas.
\end{abstract}

Palavras-chave : Metas de socialização. Estratégias de ação. Contexto.

\section{INTRODUÇÃO}

O sistema de crenças, de modo geral, tem despertado o interesse de pesquisadores que tentam compreender sua origem e repercussão nas práticas da vida cotidiana de indivíduos e grupos sociais. De modo particular, a Psicologia do Desenvolvimento tem destacado a importância do sistema de crenças e práticas de cuidado parentais ao considerar as suas possíveis repercussões na qualidade do cuidado e desenvolvimento infantil. Neste sistema de crenças estão inseridas as expectativas ou metas que os pais têm acerca da criação de filhos.

Alguns estudos enfatizam a importância das metas parentais nas práticas de cuidado infantil. Kuczynski ${ }^{1}$ salienta a importância do estudo das metas parentais considerando o contexto no qual

\footnotetext{
Este artigo é derivado da dissertação de mestrado "Metas, estratégias e práticas maternas na criação de filhos em contextos socioeconômicos distintos", defendida no Programa de Pós-Graduação em Psicologia da Universidade Federal da Bahia, pela primeira autora e orientada pela segunda. E-mail: rovicarvalho@uol.com.br

** Universidade Federal da Bahia.

*** Universidade Estadual do Rio Janeiro.
} 
estão inseridas. As metas parentais são definidas como resultados desejáveis para pais e/ou criança relativamente específicas de acordo com o contexto em que a criança vive e nas tarefas de socialização. Deste modo, as metas servem como um veículo através do qual os pais traduzem os valores parentais globais em ações específicas e como um mecanismo para organizar essas ações.

Por outro lado, há indicações na literatura das crenças parentais sobre teorias do desenvolvimento repercutindo nas estratégias adotadas. Estudo realizado por $\mathrm{Sigel}^{2}$, que abordou o desenvolvimento da competência representacional das crianças, revelou relações significativas entre crenças parentais sobre constructos desenvolvimentais e estratégias dos pais. Os pais que acreditavam que as crianças adquirem conhecimento através de seus próprios atos, de pensamentos e raciocínio tendiam a indicar o uso de estratégias de distanciamento para ensinar as crianças; enquanto que os pais que adotavam estratégias de autoridade e mais didáticas acreditavam que as crianças aprendiam através da instrução direta.

Outro estudo é o realizado por Palacios et al. ${ }^{3}$, que investigaram a relação entre três tipos de perfis de pais, definidos pelas suas idéias sobre desenvolvimento e educação infantil e seu comportamento educacional para com seus filhos. Estes pais foram caracterizados como tradicionais, modernos ou paradoxais, com base em estudos anteriores que utilizaram amostras longitudinais. Outro objetivo deste estudo foi analisar, por um lado, a relação entre crenças e comportamento educacional dos pais, e por outro lado, as conseqüências no desenvolvimento da criança. Os resultados indicaram a existência de relações entre as crenças parentais e o emprego de estratégias no relacionamento com seus filhos. Observou-se que os pais que podiam estimular de maneira produtiva o comportamento de seus filhos mostraramse mais eficientes em adequar suas demandas às capacidades das crianças.

Entretanto, os estudiosos que se interessam por esse tema na tentativa de compreender a homogeneidade e heterogeneidade das crenças e práticas parentais de criar filhos tentam explicar essa variabilidade considerando possíveis influências da cultura (países, regiões, etc.) e contextos (urba- nos x rurais; diferentes níveis socioeconômicos) em que os indivíduos ou grupos participam. Deste modo, existem diferentes visões ao considerar a relação entre a cultura e as crenças parentais.

Das perspectivas teóricas disponíveis na literatura que abordam as crenças, algumas apresentam ênfases na cultura de modo mais amplo, outras destacam, além da cultura em geral, os contextos de desenvolvimento e as condições ambientais (recursos disponíveis) que podem repercutir nos sistemas de crenças parentais.

Dentre as abordagens teóricas que privilegiam questões que dizem respeito às crenças, valores e atitudes relacionando-as à cultura de modo mais amplo e que têm influenciado a psicologia, temos o constructo do individualismo/coletivismo. Na concepção de Triandis ${ }^{4}$, as orientações para o individualismo/coletivismo, de certo modo, identificam uma sociedade e podem ser vistas como síndromes culturais. Esse constructo tem sido utilizado na área da Psicologia Transcultural para explicar as diferenças de comportamentos entre as culturas, com possibilidade de identificar aqueles específicos de cada cultura, como também os comportamentos semelhantes encontrados em culturas distintas.

Uma outra perspectiva semelhante à orientação individualismo/coletivismo, e que aborda o estudo das crenças parentais e a influência da cultura no sentido mais amplo neste sistema de crenças é o co-construtivismo; porém, o coconstrutivismo considera que a influência da cultura nas crenças é mais atenuada, uma vez que há uma interação de um sistema constituído pelo indivíduo e a cultura, e incorpora o organismo como um agente neste processo interacional.

Uma concepção que salienta a influência da cultura, porém de modo mais restrito, nas crenças e práticas de cuidado infantil, é a proposta de nicho desenvolvimental elaborada por Harkness e Super ${ }^{5}$, que ressalta a importância do contexto no desenvolvimento humano, no qual estão inseridas as crenças e práticas parentais. $\mathrm{O}$ conceito de nicho desenvolvimental favorece uma complementação à perspectiva do co-construtivismo mencionada anteriormente, uma vez que este conceito fornece um aparato conceitual que 
possibilita situar as diversas influências extrínsecas ao organismo no seu desenvolvimento. As influências podem estar em diferentes níveis ao considerar o ambiente físico e social, as práticas de cuidado e as características psicológicas dos cuidadores.

Outra perspectiva que enfatiza a influência da cultura nos sistemas de crenças parentais é a psicologia evolucionária. Contudo, esta perspectiva considera haver uma interação ou influência recíproca entre as condições ambientais (recursos), crenças culturais e comportamento individual porque ressalta não só a importância da cultura circundante, mas as circunstâncias ecológicas relevantes que exercem efeitos nas etnoteorias parentais reconstruídas por cada indivíduo. As etnoteorias parentais são consideradas por Harkness e Super ${ }^{5}$ modelos culturais que emergem através de entendimentos compartilhados e servem de moldura para as experiências, interpretações, inferências e objetivos para ações.

Apesar das diferentes perspectivas teóricas citadas, é possível constatar uma aproximação nos arcabouços teóricos do co-construtivismo proposto por Lightfoot e Valsiner ${ }^{6}$ e do nicho desenvolvimental proposto por Harkness e Super ${ }^{5}$ ao enfatizarem como o sistema de crenças da cultura mais ampla repercute nas ações e cognições parentais. As duas orientações advogam que as idéias parentais emergem da coletividade social. Por outro lado, podemos sugerir a existência de uma aproximação do conceito de nicho ecológico e a perspectiva da psicologia evolucionária, na medida em que ambas incorporam os recursos e materiais disponíveis presentes tanto na ênfase dada ao ambiente físico e social (nicho ecológico), quanto nas condições relevantes dos contextos ecológicos (psicologia evolucionária). Entretanto, ao confrontarmos estes arcabouços teóricos com a proposta da Psicologia evolucionária é notável um distanciamento no que diz respeito à visão de contexto cultural.

A cultura, nesta perspectiva, é vista como reconstruída e essa reconstrução é possível graças a mecanismos psicológicos que, a partir da observação e inferência, favorecem a reconstrução das representações mentais dos outros indivíduos que compartilham o mesmo mundo social.
As distintas perspectivas mencionadas representam os esforços de pesquisadores que tentam explicações plausíveis para a variabilidade de crenças e práticas parentais de criação de filhos encontrada em grupos de diferentes culturas, e também em grupos ou indivíduos que compartilham uma mesma cultura. No entanto, ainda não há uma teoria que integre de modo coerente e satisfatório as diversas variáveis que podem explicar tal variabilidade.

O presente estudo pretende considerar aspectos específicos e importantes como as metas de socialização que os estudos sugerem influenciar o sistema de crenças parentais de criação de filhos e que são uma lacuna nos estudos brasileiros. Na revisão de literatura realizada foi possível constatar que os estudos brasileiros que enfocam as cognições parentais de um modo geral, as práticas de cuidado e estilos parentais vêm se ampliando, embora ainda não sejam muito expressivos. Podemos citar os estudos realizados por Biasoli-Alves ${ }^{7}$ sobre a família brasileira do século XX e as práticas de cuidados da criança. Os resultados dos seus estudos sugerem que mudanças significativas e mais aceleradas têm ocorrido após a década de 50 favorecendo novas formas de organização nas famílias e nas relações entre os seus membros repercutindo nas metas de socialização adotadas pelos pais. Também o estudo realizado por Lordelo et $\mathrm{al}^{8}$ investigou o ambiente doméstico enfocando a responsividade materna às demandas da criança e atitudes em relação à maternidade e à criança. Os resultados sugerem que há pouca diferença no grau de satisfação com a maternidade das mães que participaram do estudo, porém no que diz respeito à autonomia da criança foram encontradas diferenças significativas relacionadas ao bairro de moradia e ao nível de escolaridade.

Considerando a lacuna encontrada na literatura brasileira de estudos que, de modo específico, abordem as metas e práticas parentais valorizadas por pais brasileiros, o presente estudo propõe explorar o problema da possível variabilidade das crenças parentais na criação de filhos considerando o contexto de modo mais restrito, enfocando as metas de socialização e 
estratégias valorizadas pelas mães de Salvador de níveis socioeconômicos elevado e baixo.

Diante das possíveis influências de valores culturais mais amplos, da cultura e contextos ecológicos de criação nas crenças e práticas parentais de cuidado infantil, o presente estudo foi planejado para investigar mães que participam de uma mesma cultura, na medida em que compartilham a mesma língua, moram no mesmo país e cidade, permitindo algumas comparações e relações, como por exemplo: as crenças - a partir das metas e estratégias mencionadas - das mães de Salvador são semelhantes às das mães de outros países, conforme pesquisas encontradas na literatura? As metas e as estratégias de mães de níveis socioeconômicos distintos (elevado e baixo) de Salvador consideradas neste estudo diferem ou são semelhantes entre si?

Assim, o estudo teve como objetivos: Caracterizar as mães a partir das metas e estratégias adotadas na criação de filhos; relacionar as metas e as estratégias maternas adotadas na criação de filhos; relacionar as características sócio-demográficas das mães (idade, nível de escolaridade, prestígio ocupacional, renda, estado civil, local onde reside, número e sexo dos filhos) e as metas de socialização mencionadas.

\section{MÉTODO}

\section{Participantes e contexto}

Foram entrevistadas 50 mães sendo que destas, 25 residiam no bairro de ocupação popular e 25 residiam em bairros de ocupação de classe média da cidade de Salvador. Os participantes oriundos de famílias pobres com domicílio no bairro de ocupação popular foram selecionados não aleatoriamente, mas por acessibilidade, através da indicação de uma informante e mães que residiam neste bairro, favorecendo o acesso do pesquisador e auxiliares de pesquisa às famílias. A escolha dos participantes provenientes de bairros da classe média foi também realizada não aleatoriamente e sim por acessibilidade, através da indicação de mães de classe média que os pesquisadores conheciam e das mães que foram entrevistadas visando facilitar os contatos iniciais.

Todas as mães tinham pelo menos um filho com idade entre 0 a 3 anos e além do status socioeconômico distinto, os grupos de mães variavam quanto à faixa etária, nível de escolaridade, renda, atividade ocupacional, número e sexo dos filhos.

\section{Instrumentos e coleta de dados}

Visando alcançar os objetivos do presente estudo, foram utilizados dois instrumentos básicos. $\mathrm{O}$ primeiro instrumento foi uma ficha de informações sócio-demográficas com o objetivo de coletar dados sobre idade, estado civil, local de nascimento (interior ou capital), nível de escolaridade, atividade profissional, renda pessoal e familiar das mães e seus cônjuges, número e idade dos filhos. Estes dados foram utilizados para analisar a variável nível socioeconômico da amostra através da Escala de Avaliação de Status Socioeconômico de Hollingshead ${ }^{4}$. Esse indicador de índice do nível socioeconômico utiliza os seguintes fatores: sexo, estado civil, nível de escolaridade e prestígio ocupacional.

O segundo instrumento foi uma Entrevista de Metas de Socialização (SGI -Socialisation Goals Interview) proposta por Miller e Harwood ${ }^{9}$. Esta entrevista é semi - estruturada, composta de quatro questões abertas elaboradas por Harwood, feitas às mães individualmente com o objetivo de saber as qualidades que as mães gostariam e não gostariam que seu filho tivesse quando adulto, e descrição de crianças observadas que possuem as qualidades positivas e negativas mencionadas. Além dessas questões, foram acrescentadas duas outras propostas pelo grupo de pesquisadores coordenados pela $\operatorname{Prof}^{\mathrm{a}} \mathrm{Dr}^{\mathrm{a}}$ Maria Lúcia Seidl de Moura que buscam saber o que as mães acham necessário para desenvolver as qualidades e o que elas acham que é necessário fazer e que só depende delas ao exercer o seu papel de mãe no intuito de obter as estratégias de ação que as mães utilizam para alcançar as metas relatadas.

A aplicação dos instrumentos foi realizada a partir de entrevistas estruturadas e semi-estruturadas com as mães no ambiente doméstico. A 
entrevista estruturada teve como objetivo obter dados sócio-demográficos e a entrevista semi-estruturada abordou as metas e estratégias de socialização.

As entrevistas sobre metas de socialização foram gravadas em fitas cassete e depois transcritas na íntegra. Na entrevista para obter os dados sóciodemográficos, as pesquisadoras leram todos os itens e marcaram a opção escolhida pela mãe. Esta modalidade foi adotada para todas as mães da amostra com o objetivo de evitar constrangimentos para aquelas com dificuldades na leitura.

\section{Tratamento e análise dos dados}

Ficha sócio-demográfica

Os dados sócio-demográficos foram analisados de acordo com a Escala da Avaliação de Status socioeconômico de Hollingshead ${ }^{+}$. A avaliação do nível de escolaridade levou em conta o número de anos de escolarização formal, e foi tabulada em uma escala de 7 níveis ( 1 - ensino fundamental incompleto a 7 - pós-graduação). O prestígio ocupacional foi avaliado com base numa lista com aproximadamente 450 atividades profissionais e tabulado em uma escala de 9 níveis. Empregados não qualificados e empregados domésticos receberam a menor pontuação na escala, 1 , ao passo que, executivos e profissionais liberais receberam a maior pontuação da escala, 9.

Para avaliação do status socioeconômico das mães foi computado o Four Factor Index of Social Status de Hollingshead. Esse índice foi calculado, para cada mãe e pai, somando-se o nível educacional de cada cônjuge multiplicado por 3 com o prestígio ocupacional multiplicado por 5. Dessa forma o HI produz um escore que varia de 8 a 66 que foram distribuídos em cinco faixas, conforme a escala de avaliação de Hollingshead. Essas cinco faixas foram divididas ao meio e as mães que alcançaram um escore de 8 a 34 pontos foram consideradas de status socioeconômico baixo e aquelas que alcançaram uma pontuação entre 35 a 66 pontos foram consideradas de status socioeconômico elevado. A partir das variáveis pessoais das mães (idade, nível de escolaridade, atividade ocupacional, renda familiar, religião, local de nascimento, tipo do bairro de moradia, situação conjugal e número de filhos) e variáveis pessoais da criança e do casal (idade e sexo da criança, moradia da criança, e convivência pai /mãe) obteve-se a distribuição percentual das variáveis por grupos de mães (NSE elevado e NSE baixo).

Entrevista sobre metas de socialização

Os dados obtidos na entrevista sobre metas de socialização foram tratados conforme a categorização proposta por Miller e Harwood ${ }^{9}$. Esses autores codificaram todas as respostas nas categorias elaboradas e que foram traduzidas por uma equipe de pesquisadores coordenados pela Prof ${ }^{a}$ Dr $^{\mathrm{a}}$ Maria Lúcia Seidl de Moura. Essas categorias são mutuamente exclusivas:

1) Auto-aperfeiçoamento: preocupação com que a criança se torne autoconfiante e independente, e que desenvolva totalmente seus talentos e capacidades como indivíduo.

2) Autocontrole: preocupação com que a criança desenvolva a capacidade de controlar os impulsos negativos de ganância, agressão e egocentrismo.

3) Emotividade: preocupação com que a criança desenvolva a capacidade para intimidade emocional com outros. E que seja amada (calor emocional pessoal, principalmente diádico ou dentro da família).

4) Expectativas sociais: preocupação com que a criança atenda às expectativas sociais de ser trabalhador, honesto e seguidor das leis, quando adulto.

5) Bom comportamento: preocupação com que a criança se comporte bem, se dê bem com os outros, e desempenhe bem papéis esperados (bom pai, boa mãe, boa esposa, etc.), especialmente em relação à família.

Das cinco categorias, foram criadas por Harwood et al ${ }^{10}$ subcategorias em quatro delas. $\mathrm{Na}$ categoria de Auto-aperfeiçoamento existem três subcategorias: "Bem estar emocional, físico e integração (sentir-se bem consigo mesmo)";

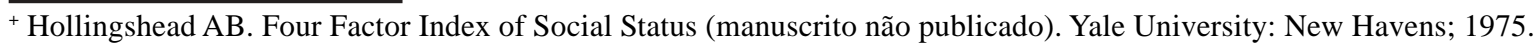


"Desenvolvimento do potencial pessoal e econômico" e "Desenvolvimento (ou independência) psicológico". Na categoria Emotividade foram incluídas as subcategorias "Calor emocional" e "Relações próximas com a família". Na categoria Expectativas sociais foram incluídas duas subcategorias: "Evitar comportamento ilícito" e "Integridade pessoal e valores religiosos". E, finalmente, na categoria Bom comportamento foram consideradas as subcategorias "Respeitador, bem educado" e "Obrigações relacionadas a papéis na família". As respostas às quatro primeiras perguntas da entrevista de metas de socialização foram codificadas conforme estas categorias. No que diz respeito às duas últimas perguntas, as respostas encontradas foram classificadas em termos de possíveis estratégias de ação: Centradas em si - são baseadas nos recursos próprios das mães (ser modelo ou oferecer modelos, disciplinar, aconselhar, ensinar por demonstração ou participação) e Centradas no contexto - são baseadas num contexto externo e que independe mais ou menos do que a mãe vai fazer (oferecer boas oportunidades sociais, dar educação de qualidade, propiciar experiências boas).

A categorização desses dados foi realizada conforme a metodologia empregada por Harwood et $\mathrm{al}^{10}$, a partir de palavras e frases descritoras. Em seguida, foram criadas as variáveis, o número total de descritores e calculado o percentual médio de respostas das mães em cada variável (categoria e subcategoria) em relação ao número total de respostas obtidas.

\section{RESULTADOS}

\section{Variáveis sócio - demográficas}

Ao analisar o nível de escolaridade das 50 mães foi possível observar que a maior concentração está nos níveis de escolaridade de ensino fundamental incompleto $(34,0 \%)$ e o ensino médio completo $(20,0 \%)$. Apenas uma das mães nunca foi à escola.

Em relação à atividade ocupacional, observa-se que nos dois grupos de mães há um percentual expressivo $(56,0 \%)$ que não exercem atividade ocupacional remunerada. Nas mães que trabalham foi possível constatar que $12,0 \%$ desempenham funções como técnicas ou são micro empresárias, enquanto que 8,0\% são administradoras, profissionais liberais com prestígio ocupacional menor (por ex: enfermeira) ou atuam como empregadas não qualificadas e empregadas domésticas, enquanto que um percentual de 2,0\% atua como trabalhadoras não especializadas; trabalhadoras semi-especializada e auxiliares de escritório, vendedoras.

No que diz respeito à renda familiar mensal, um percentual elevado das mães $(42 \%)$ tem uma renda familiar acima de $\mathrm{R} \$ 2.000,00$, enquanto que $28,0 \%$ têm uma renda de até um salário mínimo.

Quando as rendas familiares dos grupos são comparadas é possível perceber algumas diferenças relevantes. As mães de NSE elevado $(86,4 \%)$ possuem uma renda familiar na faixa acima de $\mathrm{R} \$ 2.000,00$ e nenhuma tem uma renda abaixo de $\mathrm{R} \$ 260,00$, enquanto que metade das mães de NSE baixo tem uma renda familiar na faixa de até um salário mínimo de R \$260,00 e um percentual de $32,1 \%$ na faixa de $\mathrm{R} \$ 260,00$ a $\mathrm{R} \$ 520,00$. A renda familiar média das mães de NSE elevado é de R $\$ 4.585,45$, enquanto que das mães de NSE baixo é de aproximadamente dois salários mínimos ( $\mathrm{R} \$ 575,00)$.

A maior parte das mães da amostra e de ambos os grupos está na faixa etária de 20 a 30 anos (sendo a média 29,50 para mães de elevado NSE e 27,79 para as mães de baixo NSE). O grupo de mães de NSE baixo tem um percentual maior de mães mais jovens com menos de 20 anos $(14,3 \%)$ e nenhuma na faixa etária de 40 a 50 anos.

No que diz respeito ao estado civil, no total da amostra de mães 36,0\% são casadas e 64,0\% são solteiras. Porém, os dados das mães casadas refletem o estado civil oficial destas mães, enquanto que as solteiras representam a situação conjugal na medida em que mais da metade vive junto ao companheiro e pai da criança $(54,0 \%)$ e apenas $10,0 \%$ são solteiras propriamente ditas. Quando comparamos os grupos é possível verificar que a maioria das mães casadas $(30,0 \%)$ pertence ao grupo de NSE elevado e apenas $6,0 \%$ das mães ao grupo de NSE baixo. 
Em relação ao número de filhos das mães da amostra, os maiores percentuais estão relacionados à quantidade de dois filhos $(48,0 \%) \mathrm{e}$ um filho $(42,0 \%)$. Nenhuma mãe tem mais de quatro filhos. Quando comparamos os resultados dos grupos, o maior percentual encontrado nas mães de ambos os grupos também é de um a dois filhos. A maioria das mães de NSE elevado $(59,1 \%)$ tem um filho, enquanto que mais da metade das mães de NSE baixo tem dois. É possível observar que nenhuma mãe de NSE elevado tem mais de três filhos. Este resultado sugere que as mães de ambos os grupos controlam a natalidade considerando que um percentual expressivo das mães dos dois grupos encontra-se na faixa de 20 a 30 anos. Além disso, um fato que não deve ser desprezado é o ingresso da mulher no mercado de trabalho que, de certa maneira, favoreceu às mães optar por menos filhos, como também a possibilidade de ter filhos com idade mais avançada.

\section{Metas de socialização}

As análises das entrevistas sobre metas de socialização foram baseadas nas respostas das mães a seis questões abertas. As respostas das primeiras quatro questões foram codificadas em cinco categorias e as freqüências médias dos grupos foram comparadas através da análise de variância (ANOVA). As questões 5 e 6 foram dimensionadas quanto a estratégias de ação e codificadas em duas categorias: centradas em si e centradas no contexto.

$\mathrm{Na}$ Tabela 1 podemos observar que as categorias mais importantes para a amostra total de mães foram: Expectativas sociais $(38,4 \%)$; Auto-aperfeiçoamento $(21,7 \%)$ e Bom comportamento $(20,1 \%)$.
Ao comparar os resultados dos grupos de mães é possível observar que nas respostas das mães de NSE elevado e baixo, há um predomínio da categoria Expectativas sociais (respectivamente $39,2 \%$ e 37,5\%). Em relação às metas da categoria Auto-aperfeiçoamento, as mães de NSE elevado enfatizaram-na em segundo lugar $(20,7 \%)$, enquanto que as mães de NSE baixo a consideraram como a terceira mais importante $(22,6 \%)$. No entanto, ao observarmos as metas relacionadas à categoria $\mathrm{Bom}$ comportamento dá-se o oposto. Nas respostas das mães de NSE elevado houve um predomínio menor em relação às respostas das mães de NSE baixo.

Quando o percentual médio das respostas dos grupos foi comparado pôde-se observar que o percentual médio das respostas relacionados às categorias Expectativas sociais; Auto-aperfeiçoamento e Emotividade não apresentaram grandes diferenças entre os dois grupos. Porém, em relação à categoria Bom comportamento, as respostas das mães de NSE baixo apresentaram um percentual médio maior $(24,2 \%)$ do que as mães de NSE elevado $(16,0 \%)$. A categoria de menor incidência entre as mães de NSE elevado e baixo foi a de Emotividade e a que apresentou maior diferença entre o grupo de mães foi a de Autocontrole.

Estes resultados podem ser analisados nos termos utilizados por Kohn (apud ${ }^{11}$ ) e seus estudos anteriores que indicaram que as mães de NSE baixo tendem a valorizar qualidades como a obediência e conformidade às prescrições sociais, enquanto que as mães de NSE elevado enfatizam qualidades como autoconfiança e habilidades relacionadas ao desempenho pessoal. Nas qualidades mais valorizadas pelas mães de NSE baixo no presente estudo é possível constatar uma ênfase nas metas de interdependência, ao considerar que nas metas relacionadas ao bom comportamento, há uma preocupação com adequação do comportamento do indivíduo para garantir

Tabela 1 - Percentual médio das respostas das mães conforme as categorias

\begin{tabular}{|c|c|c|c|c|c|c|c|}
\hline \multirow[t]{2}{*}{ CATEGORIAS } & \multicolumn{2}{|c|}{ Total } & \multicolumn{2}{|c|}{ NSE Elevado } & \multicolumn{2}{|c|}{ NSE Baixo } & \multirow[t]{2}{*}{ Sig. } \\
\hline & Média & DP & Média & DP & Média & DP & \\
\hline Auto-aperfeiçoamento & $21,7 \%$ & 13,9 & $20,7 \%$ & 13,6 & $22,6 \%$ & 14,1 & \\
\hline Auto-Controle & $12,8 \%$ & 9,6 & $16,0 \%$ & 10,3 & $9,5 \%$ & 8,8 & \\
\hline Emotividade & $7,2 \%$ & 7,0 & $8,1 \%$ & 5,8 & $6,2 \%$ & 8,2 & \\
\hline Expectativas Sociais & $38,4 \%$ & 18,2 & $39,2 \%$ & 21,4 & $37,5 \%$ & 15,0 & \\
\hline Bom comportamento & $20,1 \%$ & 13,6 & $16,0 \%$ & 14,5 & $24,2 \%$ & 12,6 & \\
\hline
\end{tabular}


relacionamentos mais harmoniosos e obter uma maior aceitação do grupo, enquanto as qualidades a que as mães de NSE elevado dão maior ênfase têm por objetivo a autonomia e o sucesso pessoal, ou seja, as metas de independência. Essas diferenças podem ser pensadas em termos do contexto mais restrito, ao considerarmos que as mães de NSE baixo vivenciam um contexto que favorece ou onde são estabelecidos relacionamentos em que existe ajuda mútua entre seus membros com maior frequiência do que as mães de NSE elevado.

Vale ressaltar que, embora seja possível encontrar metas que enfatizam a interdependência ou a independência nas respostas dos grupos de mães de NSE elevado e baixo, estas metas maternas não são exclusivas de cada grupo, porque apesar dos grupos, em certo sentido, viverem na mesma cultura, existe heterogeneidade nos valores e crenças dentro do mesmo grupo, que pode ser resultado da cultura ou do nível socioeconômico. Neste sentido, podemos observar que as mães de NSE baixo também enfatizaram qualidades relacionadas ao Auto-aperfeiçoamento nas suas respostas, tanto quanto as mães de NSE elevado (respectivamente $22,6 \%$ e $20,7 \%$ ), que são pertinentes com metas de independência.

As estratégias de ação mencionadas pelas mães foram classificadas em duas dimensões: Centradas em si e Centradas no contexto. Através da Tabela 2 podemos observar que as estratégias de ação Centradas em si foram as mais ressaltadas pelas mães da amostra (80,2\%). Quando os resultados dos grupos de mães foram comparados, de modo semelhante, as estratégias de ação Centradas em si foram as mais enfatizadas pelas mães de ambos os grupos. As respostas das mães de NSE elevado alcançaram um percentual médio de 78,6\%, enquanto que, nas respostas das mães de NSE baixo, o percentual médio foi de $81,9 \%$. Ao analisar esta estratégia entre grupos, não foram encontradas diferenças significativas $(\mathrm{p}=0,36)$.
As mães de NSE elevado enfatizaram mais as estratégias Centradas no contexto nas suas respostas $(21,4 \%)$ do que as mães de NSE baixo $(18,1 \%)$. Ao analisar as respostas das mães relacionadas a esta estratégia entre grupos, percebese que, estatisticamente, são significativas ( $\mathrm{p}=$ $0,03)$. As estratégias mais citadas pelas mães estavam relacionadas à educação formal e religiosa - "colocar em escolas boas"; "colocar na Igreja" - e a contextos que possibilitem a socialização das crianças através do convívio com outras pessoas (por exemplo "conviver com irmãos, primos"); ou ainda a ambientes que favoreçam o desenvolvimento da criança de modo saudável como "ter um ambiente familiar tranqüilo". Talvez a ênfase menor dada pelas mães de NSE baixo às estratégias Centradas no contexto seja decorrente da escassez de recursos no seu próprio contexto de vida, que resulta na impossibilidade de oferecer uma educação de qualidade através da educação pública, uma vez que esta não oferece a qualidade desejada por essas mães. Na maioria das vezes, a alternativa que essas mães têm para oferecer uma educação de qualidade para seus filhos depende exclusivamente do seu esforço pessoal e não dos contextos externos disponíveis.

\section{DISCUSSÃO}

O entendimento das idéias e práticas parentais vigentes em uma dada cultura requer um esforço sistemático de descrição e reflexão sobre os dados coletados, articulando-os com os conhecimentos disponíveis sobre essa mesma cultura e sobre outras mais ou menos relacionadas, utilizando diversificadas abordagens de pesquisa. O presente estudo, utilizando alguns dos instrumentos de investigação disponíveis, privilegiou a descrição de metas de socialização valorizadas pelas mães. Os resultados encontrados a partir

Tabela 1 - Percentual médio das respostas das mães conforme as categorias

\begin{tabular}{|l|c|c|c|c|c|c|c|}
\hline \multirow{2}{*}{ ESTRATÉGIAS } & \multicolumn{2}{|c|}{ Total } & \multicolumn{2}{c|}{ NSE Elevado } & \multicolumn{2}{c|}{ NSE Baixo } & \multirow{2}{*}{ Sig. } \\
\cline { 2 - 8 } & Média & DP & Média & DP & Média & DP & \\
\hline Centradas em si & $80,2 \%$ & 41,3 & 78,6 & 39,9 & 81,9 & 42,7 & \\
\hline Centradas no contexto & $19,8 \%$ & 18,4 & 21,4 & 22,8 & 18,1 & 13,9 & $*$ \\
\hline
\end{tabular}

$\mathrm{p}<0,05^{*} ; \mathrm{p}<0,01^{* *} ; \mathrm{p}<0,001^{* * *} ; \mathrm{p}<0,0001^{* * * *}$ 
dos diferentes instrumentos devem ser agora revistos, buscando extrair uma síntese dos achados mais importantes e explorar seus significados mais gerais, examinando-os frente às teorias e estudos empíricos disponíveis.

De um modo geral, os resultados da entrevista sobre as metas de socialização indicaram que as metas mais mencionadas pelo total de mães no presente estudo foram Expectativas sociais, Autoaperfeiçoamento e Bom comportamento. Por outro lado, as metas menos enfatizadas pelas mães foram as relacionadas à Emotividade e Autocontrole. Esses resultados são semelhantes aos encontrados no estudo sobre metas de socialização de mães latinas realizado por Harwood et $\mathrm{al}^{11}$ no qual encontraram diferenças nas metas de socialização das mães estudadas (latinas e euro-americanas). As mães latinas, do mesmo modo que as mães baianas, enfatizaram mais, nas suas respostas, as metas relacionadas a Expectativas sociais, Autoaperfeiçoamento e Bom comportamento e as metas menos ressaltadas também foram Emotividade e o Autocontrole. Esses achados, diferentes dos resultados encontrados para as mães euroamericanas, que enfatizaram mais as metas de Auto-aperfeiçoamento, Autocontrole e Bom comportamento, podem sugerir a existência de um padrão de crenças com valores culturais mais amplos e disseminados numa cultura denominada latina, na qual o Brasil está inserido.

Ao compararmos as metas ressaltadas pelas mães de níveis socioeconômicos elevado e baixo, os resultados não discriminam diferenças significativas. Isso pode sugerir que não há uma forte influência da variável nível socioeconômico nas expectativas que as mães têm para seus filhos prevalecendo, provavelmente, crenças e ideologias sustentadas por mães que, no presente estudo, compartilham o mesmo contexto cultural, em sentido amplo. Como salientam alguns autores ${ }^{11}$, ${ }^{12}$, as crenças parentais refletem modelos que são, apesar de implícitos, amplamente compartilhados dentro de uma comunidade.

Evidentemente, haverá diferentes sentidos conforme a definição de comunidade, ou de grupo cultural, que é empregada. Um grupo cultural pode ser definido a partir de diferentes critérios, de acordo com o interesse em questão: valores e crenças comuns entre seus membros, relacionados a algumas características, por exemplo, etnicidade, paternidade, filiação religiosa, nível socioeconômico, dentre outras. Naturalmente, é possível falar em uma comunidade cultural baiana para alguns propósitos, mas também será possível distinguir sub-grupos, dentro dessa comunidade maior, que poderão se diferenciar em alguma dimensão selecionada, uma vez que dificilmente se pode encontrar perfeita homogeneidade numa comunidade cultural.

No presente caso, a relativa homogeneidade entre grupos de diferentes níveis socioeconômicos deve suscitar algumas reflexões quanto às razões pelas quais diferenças significativas em metas de socialização não ocorreram.

Nos estudos realizados por Kohn (apud ${ }^{11,13}$ ) foram encontradas diferenças nos valores e expectativas parentais em relação aos filhos associados ao nível socioeconômico elevado e baixo dos pais.

No presente estudo, podemos considerar algumas possibilidades que possam explicar a ausência de diferenças nas metas de socialização relacionadas ao nível socioeconômico das mães. Uma primeira é que existam diferenças entre valores e expectativas parentais, em geral, cobrindo vários aspectos, mas não quanto a este aspecto específico, metas de socialização, na forma em que elas foram investigadas; ou seja, o instrumento não conseguiria captar diferenças que, realmente, existem. Apesar do cuidado em treinar os entrevistadores, visando especialmente um clima "relaxado" durante a coleta de dados, não é possível garantir que as participantes se sentiram completamente à vontade. Por exemplo, durante a aplicação das entrevistas foi possível constatar que algumas mães de nível socioeconômico baixo falavam pouco e outras pareciam inibidas, às vezes demonstrando certo receio de responder "errado" ao que estava sendo perguntado. Também alguns aspectos do contexto dificultaram a entrevista, por exemplo, interrupções de vizinhos, familiares e filhos que tiravam a concentração da mãe durante as entrevistas. Desse modo, acreditamos que esse resultado, de certo modo surpreendente, requer mais investigação, que possa apoiar o achado. 
No que diz respeito às estratégias de ação utilizadas visando o alcance das metas de socialização mencionadas pelas mães, os resultados indicam que as mães utilizam mais as estratégias Centradas em si, ou seja, aquelas que só dependem dos seus recursos próprios, enquanto que as estratégias menos valorizadas foram aquelas Centradas no contexto, ou seja, baseadas num contexto externo e que independe mais ou menos do que a mãe vai oferecer. As mães de NSE baixo deram maior ênfase às estratégias Centradas em si, porém não houve diferença estatisticamente significativa, talvez porque as estratégias descritas estão voltadas para o desempenho do que se acredita fazer parte do papel de mãe, que inclui aspectos cognitivos e afetivos, como dar exemplos, orientar o que é certo e o que é errado, dar amor, carinho, ou seja, a participação dos pais na formação e desenvolvimento dos filhos que são idéias enfatizadas nos meios de comunicação. Como exemplo, podemos citar o estudo realizado por Seidl de Moura e Pietroluongo ${ }^{14}$ que, ao analisarem o conteúdo de oito exemplares de uma revista brasileira intitulada "Crescer em família" publicada no período de 2000 a 2003, encontraram uma percentagem maior de citações de estratégias centradas em si do que de estratégias centradas no contexto. Por outro lado, as mães de NSE elevado enfatizaram um pouco mais as estratégias Centradas no contexto, o que pode ser devido às condições de vida que favorecem a utilização de recursos externos, por exemplo, colocar os seus filhos em escolas particulares de boa qualidade, e outros contextos que favorecem a socialização e o desenvolvimento da criança (centro de atividades esportivas, cursos de línguas e computação, etc.).

Quando analisamos as estratégias adotadas por essas mães para alcançarem as suas metas é possível perceber que as mães dos dois grupos utilizam mais as estratégias de ação que são centradas nos recursos próprios, salientando aspectos afetivos e cognitivos (dar amor, carinho, dar exemplos, atenção, dar educação "doméstica"). Contudo, nos resultados, foi possível constatar que essas estratégias foram mais mencionadas pelas mães de NSE baixo, podendo sugerir influência do seu contexto imediato, refletida nos recursos disponíveis em cada contexto socioeconômico.

Assim, a relativa similaridade de metas entre grupos de diferentes status socioeconômicos não se estende totalmente às praticas valorizadas, um dado que afirma a relativa independência existente entre crenças, idéias e teorias parentais e suas práticas correspondentes. Estas últimas, ao que parecem, são mais afetadas pelas condições de vida existentes, pelo contexto mais imediato onde se vive.

\section{CONCLUSÕES}

Retomando o objetivo inicial do presente estudo - caracterizar as mães a partir das metas e estratégias valorizadas na criação de filhos podemos concluir que foi possível identificar algumas metas e estratégias valorizadas pelas mães de nível socioeconômico elevado e baixo e encontrar algumas evidências da influência do contexto mais restrito e da cultura mais ampla no modo como os pais pensam sobre criação de filhos e como isso pode refletir nas expectativas que têm sobre o futuro dos mesmos, sem ter se esgotado tal propósito.

Entretanto, não foi possível encontrar diferenças significativas nas metas e estratégias mencionadas pelas mães dos dois grupos. Esse resultado bastante inesperado, por conta da evidência acumulada na literatura quanto à influência do nível socioeconômico nas teorias e estratégias parentais de criação de filhos, refletido em suas metas de socialização, deve ser tomado cautelosamente, tendo em vista a existência de várias possibilidades de explicação, como já mencionado acima.

Algumas dessas possibilidades dizem respeito a possíveis limitações do estudo, como por exemplo utilizar como informantes pessoas de uma mesma cidade, dificultando encontrar uma possível heterogeneidade nas metas de socialização e estratégias adotadas. Por outro lado, apesar de ter-se considerado a variável nível socioeconômico, que incluiu atividade ocupacional e nível de escolaridade do casal, talvez a pouca variabilidade na faixa etária (metade das mães estão na faixa de 20 a 30 anos de idade) e 
estado civil (63\% são casadas ou têm união estável) das mães pode ter limitado a identificação de variabilidade nas metas de socialização ou ter impossibilitado um resultado mais confiável em relação à existência de heterogeneidade acerca das metas de socialização.

As limitações mencionadas poderiam ser superadas em estudos futuros que venham abordar crenças e práticas maternas na criação de filhos tendo como participantes pais e mães bra- sileiras; mães de áreas urbanas e rurais do Brasil; mães de regiões distintas do país devido à grande diversidade cultural do Brasil; utilização de uma amostra maior e mais variada, por exemplo, mães solteiras; mães que convivem com os avós dos filhos; mães primíparas; mães com mais de um filho; mães de meninos ou de meninas, etc. Essa variabilidade pode favorecer a identificação de fatores que podem explicar a heterogeneidade ou não das crenças maternas sobre criação de filhos.

\begin{abstract}
Beliefs and parental practices systems have become an important topic in developmental psychology, because of their possible repercussions on child care quality and, as a consequence, on child development. Since there are only a few Brazilian studies in this field, this study aimed at characterizing parental socialization goals and strategies valued in a sample of mothers from Salvador, relating them to their socioeconomic status. Fifty mothers (with at least a child from zero to three years old) were interviewed in their homes. Two research tools were used: Sociodemographic Inquire and Socialization Goals and Strategies Interview. The sociodemographic data were treated according to the Hollingshead Socioeconomic Status Scale and the socialization goals were grouped in categories: Self-maximization, Self-control, Lovingness, Decency and Proper Demeanor; in addition, eleven subcategories were identified. The results did not indicate statistic significant differences between the groups concerning to socialization goals, except for the Personal Integrity and Religious subcategory, related to the Decency category, more emphasized by low SES mothers. On action strategies, both groups reported preference for strategies based on their own resources (self-centered). In general, the results suggest very similar socialization goals between both groups. These results are interpreted as an expression of a relatively homogenous cultural environment respecting ideal values, a surprising finding, considering the large socioeconomic differences between the groups.
\end{abstract}

Key words: Socialization goals. Parental strategies. Context.

\section{REFERENCIAS}

1. Kuczynski L. Socialization Goals and Motherchild Interaction: strategies for long-term and short-term compliance. Development Psychology 1984; 20 (6):1061-73.

2. Sigel IE, In Kim M. The answer depends on the question. A conceptual and methodological analysis of a parent belief-behavior interview regarding children's learning. In: Sigel IE, McGillicuddy-De Lisi AV, Goodnow JJ, editors. Parental belief systems. The psychological consequences for children. Hillsdale: Lawrence Erlbaum Associates, Publishers; 1992. p.83-119.

3. Palácios J, González MM, Moreno MC. Stimulating the child in the Zone of Proximal Development: the role of parents' ideas. In: Sigel IE, McGillicuddy DeLisi AV, Goodnow
JJ, editors. Parental belief systems: the psychological consequences for children. Hillsdale: Lawrence Erlbaum Associates, Publishers; 1992. p.71-93.

4. Triandis HC. Theoretical and methodological approaches to the study of collectivism and individualism. In: Kim U., Triandis TC, Kagitçibasi Ç, Choi S-C. \& Yoon G, organizers. Individualism and collectivism: Theory, method, and applications. Thousand Oaks: Sage Publications; 1994. p.41-51.

5. Harkness S, Super C. The developmental niche: a conceptualization at the interface of child and culture. International Journal of Behavioral Development 1986; 9: 545-69.

6. Lightfoot C, Valsiner J. Parental belief systems under the influence: social guidance of the construction of personal cultures. In: Siegel IE, McGillicuddy-DeLisi AV, Goodnow JJ, 
editors, Parental belief systems: the psychological consequences for children. Hillsdale, NY: Lawrence Erlbaum Associates, Publishers; 1992. p.393-413.

7. Biasoli-Alves ZMM. Famílias brasileiras do século XX: Os valores e as práticas da educação da criança. Temas em Psicologia 1997; 3: 33-40.

8. Lordelo ER, Fonseca AL, Araújo MLVB. Responsividade do ambiente de desenvolvimento:crenças e práticas como sistema cultural de criação de filhos. Psicologia:Reflexão e Crítica 2000; 13(1): 73-8.

9. Miller AM, Harwood RL. Long-term socialization goals and the construction of infants' social networks among middle class Anglo and Puerto Rican mothers. International Journal of Behavioral Development 2001; 25(5): 450-7.

10. Harwood RL, Schölmerich A, Schulze PA. Homogeneity and heterogeneity in cultural belief systems. New Directions for Child and Adolescent Development 2000; 87: 41-50.
11. Harwood RL, Lamb ME. Leyendecker B, Schölmerich. Mothers' socialization goals and evaluations of desirable and undesirable everyday situations in two diverse cultural groups. International Journal of Behavioral Development 2002; 26 (3): 248-58.

12. Harkness S, Super CM. Culture and parenting. In: Bornstein M, editor. Handbook of parenting: Vol. 2. Biology and ecology of parenting. Mahwah: Erlbaum; 1995. p.211-34.

13. Youniss J. Parent and peer relations in the emergence of cultural competence. In: $\mathrm{H}$. McGurk H, organizer. Childhood social development: contemporary perspectives. Hillsdale: Lawrence Erlbaum Associates, Publishers; 1992. p.131-47.

14. Seidl de Moura ML, Pietroluongo DP. Ser ou não ser: metas de socialização e desenvolvimento infantil (a análise de uma revista dedicada a pais). In: Resumos do $13^{\mathrm{a}}$ semana de iniciação científica da UERJ; nov 2004; Rio de Janeiro, Brasil. Rio de Janeiro: Instituto de Psicologia da UERJ; 2004. p.306.

Recebido em 30/11/2006 Modificado em 26/01/2007 Aprovado em 10/01/2007 